\title{
Impact of prenatal screening on the birth status of fetuses with Down syndrome at an urban hospital, 1972-1994
}

Tamsen M. Caruso, BA, Marie-Noel Westgate, MEd, and Lewis B. Holmes, MD

Purpose: This hospital-based study has determined the change over time (1972-1974 and 1979-1994) in the methods of prenatal detection of fetuses with Down syndrome and the impact of elective termination on the portion that were liveborn. Mothods: Using a malformations surveillance program, all 265 affected fetuses and infants were identified among 161,560 births and elective terminations during the aforementioned period at Brigham and Women's Hospital in Boston, MA. Results: From 1972 to 1974, Down syndrome was not diagnosed in any affected infants prenatally. In the early 1980s, amniocentesis was the primary method of diagnosis; later, maternal serum screening and ultrasonography were as likely to be the first method of detection. Most couples ( $86 \%$ ) elected to terminate pregnancies with affected fetuses.

Conclusions: The effect of prenatal detection and the choice of elective termination produced a significant decrease, between 1972 and 1994, in the portion of fetuses with Down syndrome who were liveborn.

From the Department of Newhorn Medicine, Brigham and Women's Hospital: Genetics and Teratology Unit, Pediatric Service, Massachusetts General Hospital; and Departmen of Pediatrics, Harvard Medical School, Boston, Massachusetts.

Address correspondence to: L.B. Holmes, $M D$ Massachusetts General Hospital, Genetic and Teratology Unit, Warren 801, 55 Fruit Street, Boston, MA 02114-2696. E-mail: holmes.lewis@MGH.harvard.edu

(C)1998 Genetics in Medicine. All rights reserved. $1098-3600 \$ 0.00$

Key words: Down syndrome, prenatal diagnosis

\section{INTRODUCTION}

It has long been recognized that the risk of having an infant with Down syndrome increases with the age of the mother during pregnancy. When the diagnostic technique of amniocentesis became available widely in the late 1970 s and early 1980 s, it was recommended that the test be offered to older pregnant women. Age 35 years and older was established, by analyses of cost and benefit, as the maternal age at which amniocentesis should be offered routinely as an option. ${ }^{1,2}$

During the past 15 years, two additional prenatal screening tests have been offered to pregnant women younger than 35 years: 1) the routine use of maternal serum screening for high and low levels of alphafetoprotein (AFP), and later other analytes including human chorionic gonadotropin (hCG) and estriol, at 16 weeks of gestation, ${ }^{3}$ and 2) ultrasonography at 16 to 18 weeks, ${ }^{4}$ leading to the identification of structural abnormalities of the fetus. The discovery of a low level of maternal AFP or structural anomalies such as a thickened nuchal skin fold, by sonography, would prompt the offer of amniocentesis. When all of these types of prenatal screening, i.e. amniocentesis, maternal serum screening, and ultrasonography, identified a fetus with an abnormality such as Down syndrome before 24 menstrual weeks of pregnancy, the parents had the option of elective termination of the pregnancy.

In assessing the impact of prenatal diagnosis on pregnancies of fetuses with Down syndrome, it should be noted that all affected fetuses would not be expected to survive long enough to become a fullterm pregnancy. ${ }^{5,6}$ For example, Hook et al. ${ }^{5}$ reported that spontaneous fetal death occurred in $25.6 \%$ of fetuses with Down syndrome that had been detected by amniocentesis in the second trimester.
We describe a decrease in the portion of infants with Down syndrome who were liveborn at a large university hospital (Brigham and Women's Hospital [BWH] in Boston, MA) beginning before prenatal diagnosis was routine (1972-1974) and continuing from 1979 through 1994. Although this is not an unselected population of pregnant women with uniform management, this report has the advantage of including liveborn and stillborn births, as well as pregnancies with affected fetuses that were terminated electively.

\section{METHODS AND MATERIALS}

All infants and fetuses with Down syndrome were identified by an active malformations surveillance program described previously, ${ }^{7}$ which was conducted Monday to Friday until the late 1980 s when coverage on Saturday or Sunday was added. This survey begins with a review of the findings in the pediatricians' initial and discharge examinations of each infant born at this hospital. In addition, the medical records of all infants transferred to the adjacent Boston Children's Hospital, autopsy reports, prenatal ultrasound reports filed in the Newborn Intensive Care Unit, and reports from the hospital's Cytogenetics Laboratory were reviewed to identify all infants with any type of chromosome abnormality. For this study, the results of chromosome analysis were sought for each infant; if none was available, the diagnosis was based on the findings recorded in the physical examination records.

Demographic information, including the age of each parent, racial/ethnic group, insurance status, family history of birth defects, and the results of all prenatal testing, was obtained whenever possible in a postpartum interview. During the interview, the mother was asked to sign an Informed Consent Document. The process of obtaining consent was in 
accordance with the ethical standards for human experimentation established by the Declaration of Helsinki in 1975, revised in 1983. If the mother was not interviewed by the research assistant, her medical record was reviewed.

The periods surveyed were February 16, 1972 to February 14, 1975 (referred to hereafter as 1972-1974) and January 1, 1979 through December 31,1994 . (The hiatus of 4 years occurred because of a lack of space and funds to support the surveillance program.) During the study there were 159,928 livebirths, 1,303 stillbirths ( $>20$ weeks gestation), and 2,600 elective terminations (during the second trimester of pregnancy). From this total of 163,831 we subtracted all infants with other types of major malformations ( $n=1805)$, such as renal agenesis and diaphragm defects, whose mothers had been transferred to $\mathrm{BWH}$, because of the identification of a fetal abnormality at another hospital, to define the total population of 162,026 livebirths, still births, and elective terminations in the second trimester.

We assigned the mothers of affected infants to two groups, maternal nontransfers and maternal transfers. The nontransfer group included women who had always planned to deliver at this hospital. The analysis we report was carried out only on the infants of nontransfers. The transfer group included women who had planned to deliver at another hospital, but transferred their care to this hospital after a diagnosis of a fetal abnormality. From 1972 through 1974 our interviews showed that none of the mothers of infants with Down syndrome had been transferred to the hospital for delivery after the mother had prenatal screening by either sonography or amniocentesis. (Amniocentesis was used to diagnose chromosome abnormalities in three fetuses from 1972 to 1974: trisomy 18 [ 2 infants] and 47,XXY [ 1 infant]). However, this classification by transfer status was necessary in 1979 when the surveillance program resumed. The transfer status of each woman from 1979 to 1990 was assigned initially by the research assistant who had ascertained information about each infant and had either interviewed the mother or reviewed her medical record for that admission but not previous admissions. The questions asked about the mother's transfer status became more explicit when the questionnaire was revised in 1990.

Because of the importance of transfer status for this study, we reevaluated the transfer status of all affected infants identified in the years 1979 through 1990. This evaluation was done in two ways: 1) a questionnaire was sent to 218 women who had had affected infants through 1990; and 2) a review was conducted of the medical records of all mothers of affected infants who did not return the questionnaire. The short questionnaire asked about the woman's transfer status and the method of prenatal screening used. The entire medical record was reviewed for comments about where the mother had planned to deliver, whether she had had appointments at BWH during this pregnancy before any prenatal screening, and whether her last child had been born at BWH.

The infants identified prenatally were also subdivided into those identified before or after 24 weeks of gestation, because elective termination is not legal in the state of Massachusetts after the 24th menstrual week.

\section{Demographics}

Information was obtained about the portion of all postpartum women at BWH who were 35 years of age and older from other research studies ${ }^{8,9}$ and hospital reports. ${ }^{10}$

\section{RESULTS}

\section{Transfer status}

Of the 218 short questionnaires mailed, 46 were returned undelivered, 78 (45\%) women responded, and 94 did not. Eleven (14\%) of the respondents changed their transfer status: three ( $4 \%$ ) from transferred to nontransferred, and eight (10\%) from nontransferred to transferred.

Based on the research assistant's review of the 140 other medical records, the transfer status of $19(14 \%)$ women was changed: eight ( $5 \%)$ moved to nontransfer, and $11(9 \%)$ moved to maternal transfer.

\section{Cytogenetics}

Based on the results of the assessment of transfer status there were 265 nontransfer, nonmosaic affected infants and fetuses in terminated pregnancies. The results of chromosome analysis were available for 262 infants: 257 (98\%) had nondisjunction trisomy 21 , and five $(2 \%)$ had translocation trisomy 21 . The other three affected nontransfer infants were either diagnosed clinically or had cytogenetic studies performed elsewhere; the printed reports from these cases could not be obtained. Excluded from

Table 1

Prevalence rate of Down syndrome among nontransferred patients

\begin{tabular}{lccccccc}
\hline & $\mathbf{1 9 7 2 - 7 4}$ & $\mathbf{1 9 7 9 - 8 1}$ & $\mathbf{1 9 8 2 - 8 4}$ & $\mathbf{1 9 8 5 - 8 7}$ & $\mathbf{1 9 8 8 - 9 0}$ & $\mathbf{1 9 9 1 - 9 2}$ & $1993-94$ \\
\hline Total No. $^{2}$ & $20^{a}$ & $32^{b}$ & 36 & 33 & $71^{c}$ & 38 & 35 \\
No. of deliveries $^{d}$ & 18,155 & 21,405 & 25,169 & 29,970 & 31,007 & 18,410 & 17,444 \\
Prevalence all affected infants $^{e}$ & 1.05 & 1.5 & 1.4 & 1.1 & 2.3 & 2.06 & 2.0 \\
Prevalence among liveborn infants $^{f}$ & 1.05 & 1.5 & 0.9 & 0.6 & 1.06 & 0.6 & 0.8 \\
\hline
\end{tabular}

ancludes 1 translocation; prevalence without translocation is 1.05 .

${ }^{b}$ Includes 2 translocations; prevalence without translocations is 1.45 .

'Includes 2 translocations; prevalence without translocations is 2.19.

${ }^{d}$ Includes an estimated 200 elective terminations for each year after 1981; excludes all pregnancies terminated electively because of the prenatal detection of other major malformations.

'Average yearly prevalence rate of Down syndrome per 1000 births for each 2-year and 3-year grouping.

$f$ Average yearly prevalence rate of liveborn infants with Down syndrome for each 2-year and 3-year period after subtract-

ing affected stillborn infants and elective terminations. 
this report were 365 transfers, four infants whose transfer status could not be determined, and 18 with trisomy 21 mosaicism.

\section{Prevalence rate}

The prevalence rate of Down syndrome among the liveborn and stillborn infants and elective terminations among women who were nontransfers was 1.05 per 1000 for 1972 to 1974 and was higher in all subsequent years, and at or above 2.0 per 1000 between 1988 and 1994 (Table 1). The increase over time was significant $(P=0.001)$, using a Poisson test for trend analysis. When restricted to the prevalence rate of liveborn infants with Down syndrome, excluding stillbirths and elective terminations, the decrease over time was not significant $(P=0.069)$.

Included in the evaluation of this change in prevalence rate over time was a determination of the portion of all mothers of affected infants (Table 2) who were 35 years of age and older in each period. They were: 1972 to $1974: 25 \%$; 1979 to $1981: 31 \% ; 1982$ to $1984: 42 \%$; 1985 to $1987: 58 \% ; 1988$ to $1990: 56 \%$; 1991 to $1992: 68 \%$; and 1993 to $1994: 66 \%$. By comparison, the portion of all postpartum women 35 years and older at BWH was $4 \%$ in 1972 to 1974 (Holmes LB, unpublished study); $9 \%$ in 1977 to $1980^{8} ; 14 \%$ in 1983 to $1984^{9} ; 16 \%$ in 1985 to $1987^{9}$; $18 \%$ in 1988 to $1990^{\circ} ; 20 \%$ in 1991 to $1992^{9}$; and $23 \%$ in 1993 to $1994 .^{9}$

\section{Birth status}

Among affected infants of nontransferred mothers 35 years and older, all five born in the 3-year period before the advent of prenatal diagnosis (1972-1974) were liveborn (Table 2 and Fig. 1). The first impact of elective terminations on the birth sta- tus of affected infants was in the second monitored period (1979-1981), by which time half of the affected infants born to women under 35 years of age had been identified by prenatal testing. The parents chose to terminate all of those pregnancies. From 1982 through 1994 , more than $80 \%$ of the affected fetuses were identified by prenatal screening (Table 3 ), and most of these pregnancies were terminated electively. Only five $(3.7 \%)$ stillborn infants with Down syndrome were identified among the 136 affected infants ascertained from 1972 to 1974 and from 1979 to 1994 among women 35 years of age and older (Table 2).

Among the 127 nontransferred mothers younger than 35 years, the percentage of liveborn infants remained $100 \%$ until the 1982 to 1984 time when it was $86 \%$ (Fig. 2). The portion of those diagnosed prenatally rose from $10 \%$ in 1982 to 1984 to $67 \%$ in 1991 to 1992 and was $58 \%$ in 1993 to 1994 (Table 3 ). When the prenatal diagnosis of Down syndrome was determined before 24 weeks of gestation, the parents of $27(87 \%)$ of the 31 affected fetuses chose to terminate the pregnancy. Like the women 35 years and older, very few $(2.4 \% ; 3$ of 127$)$ affected infants were stillborn in the population of women younger than 35 years.

\section{Method of prenatal detection}

Among women 35 years and older, the first abnormal prenatal test result was almost always obtained through amniocentesis in the period from 1979 through 1987 (Table 3). Thereafter, the portion detected initially by ultrasound increased, primarily because physical abnormalities were identified during the sonography examination before a scheduled

Table 2

Birth status of infants and fetuses with Down syndrome

\begin{tabular}{|c|c|c|c|c|}
\hline & $\mathbf{n}$ & $\begin{array}{c}\text { Liveborn } \\
\% \\
\end{array}$ & $\begin{array}{c}\text { Stillborn } \\
\%\end{array}$ & $\begin{array}{c}\text { Elective termination } \\
\% \\
\end{array}$ \\
\hline \multicolumn{5}{|c|}{ Maternal Age $<35^{a}$} \\
\hline $1972-74$ & 15 & 100 & 0 & 0 \\
\hline $1979-81$ & 22 & 100 & 0 & 0 \\
\hline $1982-84$ & 21 & 86 & 5 & 9 \\
\hline $1985-87$ & 14 & 93 & 0 & 7 \\
\hline $1988-90$ & 31 & 58 & 7 & 35 \\
\hline $1991-92$ & 12 & 33 & 0 & 67 \\
\hline 1993-94 & 12 & 58 & 0 & 42 \\
\hline Total & 127 & & & \\
\hline \multicolumn{5}{|c|}{ Maternal Age $\geq 35^{b}$} \\
\hline $1972-74$ & 5 & 100 & 0 & 0 \\
\hline $1979-81$ & 10 & 50 & 0 & 50 \\
\hline $1982-84$ & 15 & 13 & 7 & 80 \\
\hline $1985-87$ & 19 & 26 & 0 & 74 \\
\hline $1988-90$ & 40 & 23 & 0 & 70 \\
\hline 1991-92 & 26 & 23 & 0 & 77 \\
\hline 1993-94 & 24 & 17 & 13 & 70 \\
\hline Total & 136 & & & \\
\hline
\end{tabular}




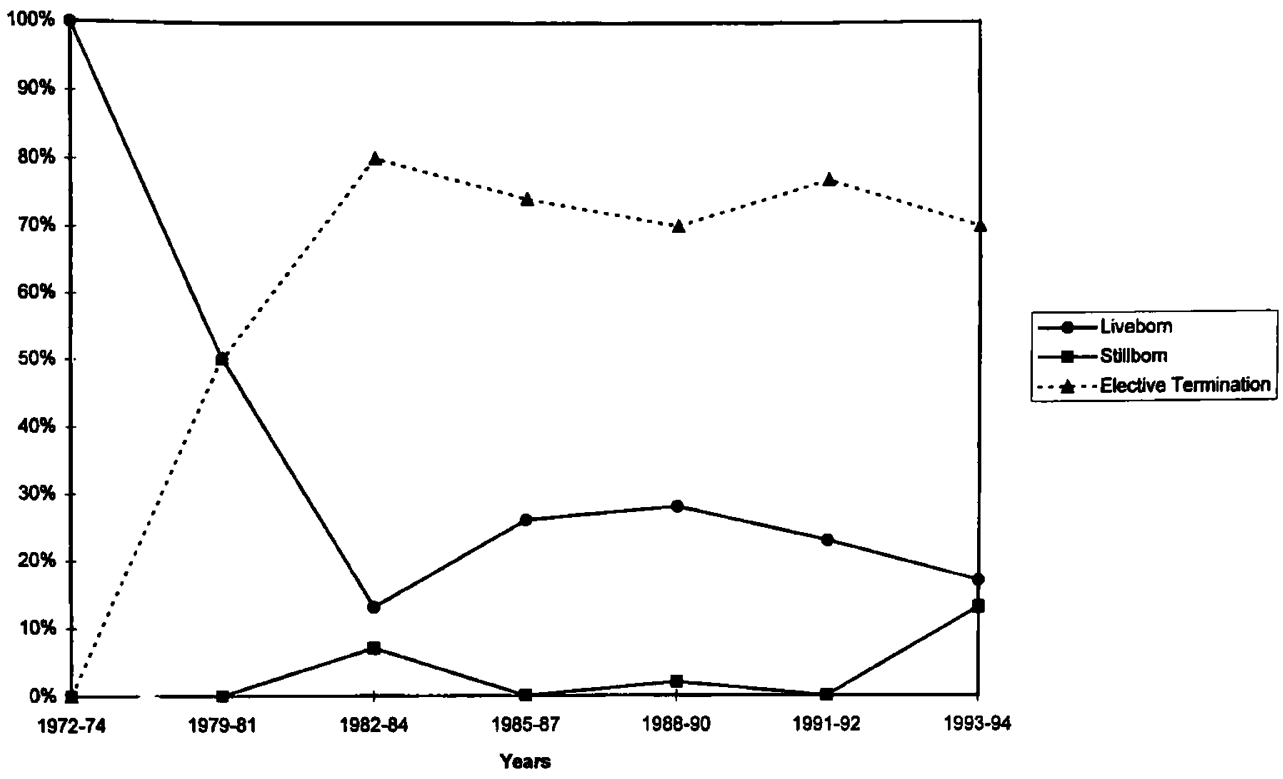

Fig. 1 Shows the increase in elective terminations to $80 \%$ by 1982 to 1984 among nontransferred mothers 35 years and older.

Table 3

Method of First Prenatal Detection

\begin{tabular}{|c|c|c|c|c|c|c|c|}
\hline & $\mathbf{n}$ & $\begin{array}{c}\text { MSAFP } \\
(\%)\end{array}$ & $\begin{array}{c}\text { US } \\
(\%)\end{array}$ & $\underset{(\%)}{\text { Amnio }}$ & $\begin{array}{c}\text { Not detected } \\
\text { before } 24 \text { wks } \\
(\%)\end{array}$ & $\begin{array}{c}\text { Detected } \\
\text { (method unknown) } \\
(\%)\end{array}$ & $\begin{array}{c}\text { Insufficient } \\
\text { information } \\
(\%)\end{array}$ \\
\hline \multicolumn{8}{|c|}{ Maternal Age $<35$} \\
\hline $1972-74$ & 15 & 0 & 0 & 0 & 100 & 0 & 0 \\
\hline $1979-81$ & 22 & 0 & 0 & 0 & 100 & 0 & 0 \\
\hline $1982-84$ & 21 & 0 & 5 & 5 & 90 & 0 & 0 \\
\hline $1985-87$ & 14 & 7 & 0 & 0 & 79 & 0 & 14 \\
\hline $1988-90$ & 31 & $16^{a}$ & 10 & 10 & 58 & 6 & 0 \\
\hline $1991-92$ & 12 & $17^{b}$ & 42 & 8 & 33 & 0 & 0 \\
\hline 1993-94 & 12 & $33^{c}$ & 25 & 0 & 42 & 0 & 0 \\
\hline Total & 127 & & & & & & \\
\hline \multicolumn{8}{|c|}{ Maternal Age $\geq 35$} \\
\hline $1972-74$ & 5 & 0 & 0 & 0 & 100 & 0 & 0 \\
\hline $1979-81$ & 10 & 0 & 0 & 60 & 40 & 0 & 0 \\
\hline $1982-84$ & 15 & 0 & 13 & 73 & 7 & 0 & 7 \\
\hline $1985-87$ & 19 & 0 & 5 & 58 & 26 & 11 & 0 \\
\hline $1988-90$ & 40 & 8 & 25 & 45 & 20 & 2 & 0 \\
\hline 1991-92 & 26 & 4 & 35 & 46 & 11 & 4 & 0 \\
\hline 1993-94 & 23 & 9 & 26 & $48^{d}$ & 13 & 4 & 0 \\
\hline Total & 136 & & & & & & \\
\hline
\end{tabular}

ancludes 3\% (1/31) detected by combined AFP/hCG screening.

${ }^{b}$ Includes $8 \%(1 / 12)$ detected by combined AFP/hCG screening.

' Includes $8 \%(1 / 12)$ detected by combined AFP/hCG/estriol screening.

dIncludes $4 \%$ detected by chorionic villus sampling.

MSAFP, maternal serum alphafetoprotein screening; AFP/hCG, maternal serum screening with two analytes; $A F P$ and human chorionic gonadotropin; Amnio, amniocentesis; US, ultrasonography. 


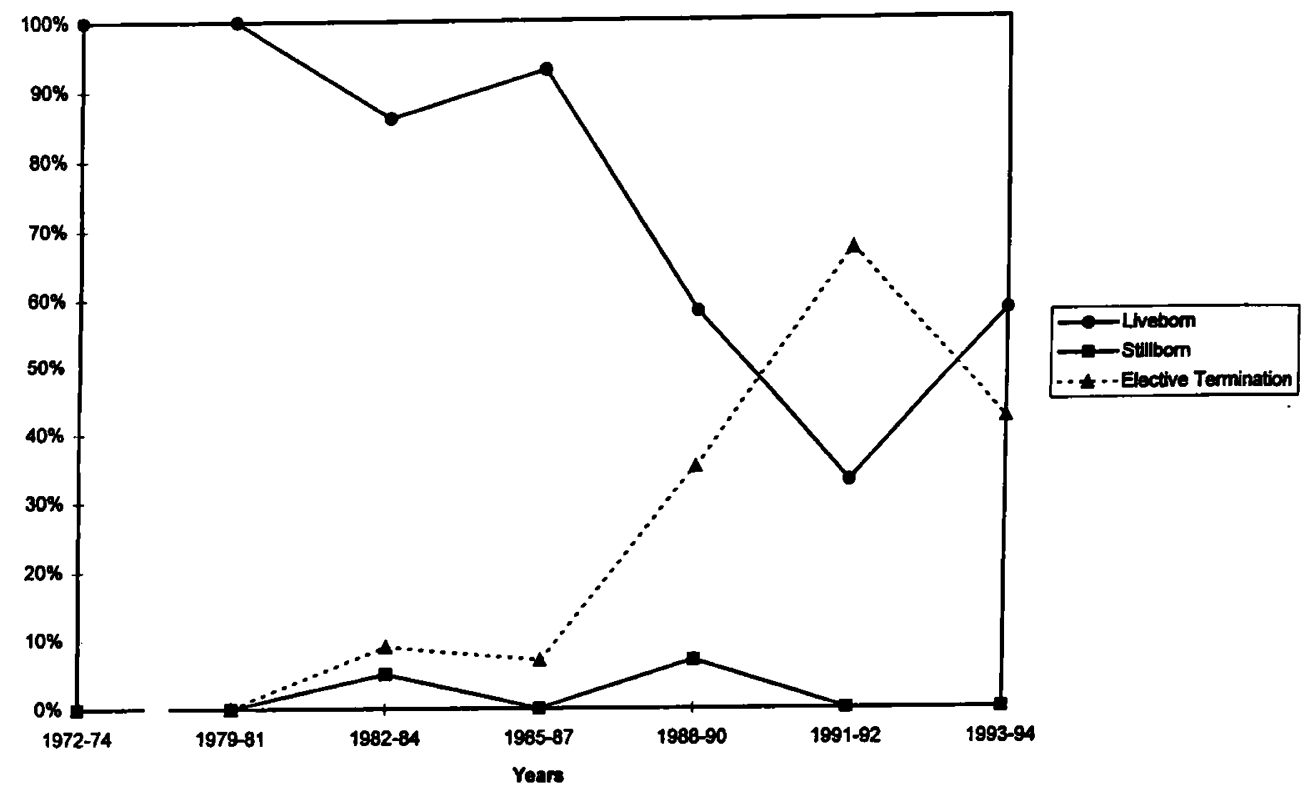

Fig. 2 Shows the increase in elective terminations to $50 \%$ to $65 \%$ by 1991 to 1992 among nontransferred mothers younger than 35 years.

amniocentesis. The most common abnormalities detected by sonography among women in both age groups were thickened nuchal folds and/or short femur ( 9 of $40 ; 23 \%)$; heart defects ( 5 of $40 ; 13 \%$ ); and cystic hygroma ( 5 of $40 ; 13 \%)$. Thirty of the 40 cases detected initially by ultrasound were noted on a preamniocentesis ultrasound to have structural anomalies and then confirmed to have trisomy 21 through the amniocentesis results. The other 10 cases first detected by ultrasound were confirmed to have Down syndrome through chromosome analysis postmortem or after being liveborn; these pregnant women did not have amniocentesis. During this study, maternal serum AFP screening was not generally recommended as a method of prenatal screening in women 35 years and older. Therefore, maternal serum AFP screening provided only a small portion (4-9\%) of the first abnormal prenatal results of women 35 years and older from 1988 to 1994.

Among women younger than 35 years, the first abnormal test results between 1982 and 1990 were more varied, including ultrasonography and amniocentesis with about equal frequency than those of maternal serum AFP (Table 3 ). The nine women who had amniocentesis in 1988 to 1994 had no special risk factors, e.g. family history of Down syndrome. Six of the nine women had amniocentesis because they were 33 to 34 years old and considered their age a sufficient age-related risk. The reasons for the other three women could not be determined from their medical records.

\section{Demographics}

The characteristics of the BWH maternity population in the years 1972 to 1974,1977 to 1980 , and 1988 to 1989 , respectively, included 1)race: white $60 \%$ to $74 \%$, black $13 \%$ to $16 \%$, Hispanic $6 \%$ to $11 \%$, and Asian $2 \%$ to $4 \%$; and 2)insurance status: private insurance or $\mathrm{HMO} 73 \%$ to $81 \%$ and government programs or no insurance $19 \%$ to $27 \%$.

\section{DISCUSSION}

The technology that makes the prenatal diagnosis of fetal abnormalities possible has evolved steadily during the time covered in this analysis (1972-1994). For example, amniocentesis was expanded to include "early" amniocentesis at 12 to 15 weeks of gestation. ${ }^{10}$ In some centers, although not this one, chorionic villus sampling at 9 to 11 weeks of gestation became a popular alternative to amniocentesis. With regard to maternal serum AFP screening, it was reported in 1984 that low levels of AFP could be a marker of Down syndrome and trisomy $18 .{ }^{11}$ Estriol and $\mathrm{hCG}^{12}$ were added as additional markers that increased the detection of fetuses with Down syndrome from $20 \%$ by AFP testing alone ${ }^{13}$ to $65 \%$ by testing which measured AFP, hCG, and estriol. ${ }^{14}$ The technical sophistication of ultrasonography and the skill of the sonographer improved during these years. Other medical centers may also have had their own areas of clinical research and participation in new innovations. For example, this hospital carried out very few chorionic villus sampling procedures, but was actively involved in the development of "early" amniocentesis as an option. ${ }^{10}$ This hospital's obstetrics clinic, which provides medical care to about 2500 pregnant women each year, instituted maternal serum AFP screening as a routine option in mid1985 and began the maternal serum triple marker screening (AFP, hCG, and estriol) in 1990. The medical care of many other pregnant women was provided by private obstetricians who instituted these screening programs at different times and used laboratories outside of the hospital. Prenatal ultrasonography has been an area of clinical research both in the hospital ${ }^{15}$ and at a large nearby private sonography office, ${ }^{10}$ an interest that has led to an increase both in skill level and awareness of sonographers. Therefore, this hospital was a setting in which the prenatal screening offered to each 
pregnant woman changed during the study years 1972 to 1994

A similar high frequency of elective termination of affected fetuses with a prenatal diagnosis $(92 \%)$ was observed in the southeastern United States through $1986^{16}$ and in England between 1989 and 1993. ${ }^{17}$

The same steady increase in the frequency of both prenatal detection and elective termination of the pregnancies with affected fetuses has been observed for other fetal abnormalities, such as anencephaly, ${ }^{18}$ spina bifida, ${ }^{19}$ and heart defects, ${ }^{20}$ at this and other medical centers. These similar patterns reflect the impact of the same technologies on the prenatal detection of abnormalities in the fetus before 24 weeks of gestation.

This study showed that the prevalence of Down syndrome was significantly higher in 1991 to 1994 than it was in 1972 to 1974 . We suggest several possible explanations for this increase. First, the increase in the prevalence rate may reflect an increase in the proportion of pregnant women 35 years and older, the high-risk group among all new mothers. The percentage of the mothers of infants with Down syndrome who were 35 years and older increased steadily from $25 \%$ in 1972 to 1974 to $66 \%$ in 1993 to 1994 (Tables 2 and 3). This increase occurred when the portion of all postpartum women 35 years and older at BWH also doubled between $9 \%$ in 1977 to 1980 and $18 \%$ in 1988 to 1989 . Similar changes have been observed in other regions. For example, Olsen et al. ${ }^{21}$ observed an increase in the proportion of infants with Down syndrome born to women aged 35 years and older, from $27.1 \%$ to $34.1 \%$, in New York state between 1983 and 1992. Olsen was reporting the findings for infants with Down Syndrome identified in a state-wide malformations registry which obtained information from birth and death certificates, a chromosome registry, and hospital reports on infants up to 2 years of age. An increase in the mean age of all mothers of infants with Down syndrome also was observed between 1980 and 1992 in north-eastern France ${ }^{22}$ and between 1989 and 1993 in England and Wales. ${ }^{23} \mathrm{Sec}-$ ond, the increase in the prevalence rate could reflect the identification of a larger number of affected infants who would not have survived to birth and would have been stillborn. Both Hook et al. ${ }^{5}$ and Snijders et al. ${ }^{6}$ reported the rate of fetal death among affected fetuses in whom Down syndrome was diagnosed by amniocentesis. The rate was $25.6 \%$ in the first study ${ }^{5}$; in the second study, ${ }^{6}$ it was estimated for women 35 years and older that the frequency of trisomy 21 at birth was $54 \%$ lower than at 9 to 14 weeks of gestation and 33\% lower than at 15 to 20 weeks of gestation. This is also suggested by the fact that only $1.3 \%$ ( 3 of 263) of the affected infants of nontransferred mothers were stillborn, which is lower than the proportion (5-10\%) estimated for chromosome abnormalities. ${ }^{24}$ Third, there may have been errors in the designation of the transfer status of the mothers of affected infants. However, we were reassured that the rate of potential misclassification is very low based on the findings in the questionnaires returned by 78 women, the findings in the detailed review of the medical records, and the high degree of correlation between the interpretation from the review and the women's responses to the study questionnaire about transfer status.
The potential biases inherent in a university hospital should be noted. Theoretically, women could have begun obstetrical care at this hospital, had prenatal diagnosis studies at another facility, terminated the pregnancy elsewhere, and never have been identified in a study like this one. Although this could have occurred, there is no evidence that such a group of women would alter the changes over time in the overall methods of detecting fetuses with Down syndrome or their status at birth, i.e. elective termination, liveborn, or stillborn.

This analysis showed that, between 1972 to 1974 and 1993 to 1994 , the portion of the infants with Down syndrome who were liveborn decreased dramatically from $100 \%$ to $58 \%$ in mothers younger than 35 years and to $17 \%$ in mothers 35 years and older. If this trend were true for a significant part of the pregnancies in the United States, there would be a marked decrease in the birth of liveborn infants with Down syndrome. A progressive decrease in the portion of liveborn infants with Down syndrome has also been observed in British Columbia, ${ }^{25}$ Wales, ${ }^{26}$ Denmark, ${ }^{27}$ Georgia, ${ }^{28}$ Maine, ${ }^{29}$ and England and Wales ${ }^{22}$ for the years 1974 to 1983,1978 to 1984,1980 to 1985,1978 to 1986,1980 to 1993 , and 1989 to 1993 , respectively. These data were more population-based and included information from a birth defects registry for a province ${ }^{25}$ and reviews of prenatal diagnosis services in a country, ${ }^{27}$ a large region, ${ }^{26}$ a state, ${ }^{29}$ and a metropolitan area. ${ }^{28}$ The greatest decrease was among women 35 years and older and varied from $23.9 \%$ in British Columbia ${ }^{25}$ for 1979 to 1983 to a projected $84.1 \%$ in Denmark for 1983 to 1985.28

This decrease will have a significant impact on the medical services used by infants with Down syndrome. However, this change in the management of pregnancies of fetuses with Down syndrome will not be detected by those public health programs, e.g. through birth certificates, which do not identify those pregnancies terminated electively because of fetal abnormalities.

\section{CONCLUSIONS}

Between 1972 and 1994 the percentage of infants with Down syndrome who were liveborn decreased dramatically. There was no prenatal detection between 1972 and 1974 . In the early 1980s, this decrease reflected the impact of amniocentesis among women 35 years and older. By the late 1980 s prenatal detection was common among women younger than 35 years and detection was by several modalities including AFP screening, sonography, and amniocentesis. When the diagnosis was established before 24 weeks of gestation, $86 \%$ to $87 \%$ of the parents chose elective termination of the pregnancy.

\section{Acknowledgments}

This project was supported at different times by grants from the Massachusetts Developmental Disabilities Fund, Merrill Dow Pharmaceuticals, the Easter Seals Research Program, the New England Regional Genetics Group, and the Peabody Foundation. We thank Louise Ryan, $\mathrm{PhD}$ for help with statistical analyses. This study benefited significantly from the diligence of many research assistants and the hospital staff in cytogenetics, pediatrics, pathology, and obstetrics. 


\section{References}

1. Ferguson-Smith MA, Yates JRM. Maternal age-specific rates for chromosomal aberrations and factors influencing them: Report of a collaborative study on 52,965 amniocenteses. Prenat Diagn 1984;4:5-44.

2. Hook EB, Cross PK, Regal RR. The frequency of $47,21,47$, +18 , and $47,+13$ at the upper-most extremes of maternal ages: Results on 56,094 fetuses studied prenatally and comparison with data on livebirths. Hum Genet 1984;68:211-220.

3. DiMaio MS, Baumgarten A, Greenstein RM, Saal HM, Mahoney MJ. Screening for fetal Down's syndrome in pregnancy by measuring maternal serum alpha-fetoprotein levels. N Engl J Med 1987;317:342-346.

4. Benacerraf BR, Gelman R, Frigoletto FD. Sonographic identification of second-trimester fetuses with Down's syndrome. N Engl J Med 1987;317:1371-1376.

5. Hook EB, Topol BB, Cross PK. The natural history of cytogenetically abnormal fetuses detected at midtrimester amniocentesis which are not terminated electively: New data and estimates of the excess and relative risk of late fetal death associated with $47,+21$ and some other abnormal karyotype. Am J Hum Genet 1989;45:855-861.

6. Snijders RJ, Holzgreve W, Cuckle H, Nicolaides KH. Maternal age-specific risks for trisomies at 9-14 weeks' gestation. Prenat Diag 1994;14:543-552.

7. Nelson K, Holmes LB. Malformations due to presumed spontaneous mutations in newborn infants. $N$ Engl J Med 1989;320:19-23.

8. Lieberman E, Ryan KJ, Monson RR, Schoenbaum SC. Medical and socioeconomic characteristics accounting for racial differences in the rates of premature births. $N$ Engl J Med 1987;33:3-7.

9. Department of Obstetrics and Gynecology. Annual reports, 1983 to 1994, from the Department of Obstetrics and Gynecology, Brigham and Women's Hospital, Boston, MA.

10. Benacerraf BR, Greene MF, Saltzman DH, Barss VA, Penso CA, Nadel AS, et al. Early amniocentesis for prenatal cytogenetic evaluation. Radiology 1988;169:709-10.

11. Merkatz IR, Nitowsky HM, Macri JN, Johnson WE. An association between low maternal serum alpha-fetoprotein and fetal chromosome abnormalities. Am J Obstet Gynecol 1984;148:886-894.

12. Goodbum SF, Yates JRW, Raggatt PR, Carr C, Ferguson-Smith ME, Milton PJD, et al. Second trimester maternal screening using alpha-fetoprotein, human chorionic gonadotrophin and unconjugated oestriol: Experience of a regional program. Prenat Diag 1994;14:391-402.

13. Wu LB. Maternal serum $\alpha$-fetoprotein screening and Down's syndrome. Am J Obstet Gynecol 1986;155:1362-1363.
14. Haddow JE, Palomaki GE, Knight GJ, Williams J, Pulkkinen A Canick J, et al. Prenatal screening for Down's syndrome with use of maternal serum markers. N Engl JMed 1992,327:588-593.

15. Benson CB, Bieber FR, Genest DR, Doubilet PM. Doppler demonstration of reversed umbilical blood flow in an acardiac twin. J Clin Ultrasound 1989;17:291-295.

16. Vincent VA, Edwards JG, Young SR, Nachtigal M. Pregnancy termination because of chromosomal abnormalities: A study of 26,950 amniocenteses in the southeast. South Med J 1991;84:1210-1213.

17. Alberman E, Mutton D, Ide R, Nicholson A, Bobrow $M$ Down's syndrome births and pregnancy terminations in 1989 to 1993: Preliminary findings. Br J Obstet Gynaecol 1995;102:445-447.

18. Limb C, Holmes LB. Anencephaly: Changes in prenatal detection and birth status, 1972 through 1990. Am J Obstet Gynecol 1994;170:1333-1338.

19. Brower C, Raymond M, Lamley J, Bury G. Trends in neural tube defects 1980-1989. Med J Aust 1993;158:152-154.

20. Sharland G. Changing impact of fetal diagnosis of congenital heart disease. Arch Dis Child Fetal Neonatal Ed 1997;77:F1-F3.

21. Olsen CL, Cross PK, Gensburg LJ, Hughes JP. The effects of prenatal diagnosis, population ageing, and changing fertility rates on the live birth prevalence of Down syndrome in New York State, 1983-1992. Prenat Diagn 1996;16:991-1002.

22. Stoll C, Alembik Y, Dott B, Roth MP. Recent trends in the prevalence of Down syndrome in north-eastern France. Ann Genet 1994;37:179-183.

23. Anderman $E$, Mutton $D$, Ide R, Nicholson A, Bobrow M. Down's syndrome births and pregnancy terminations in 1989 to 1993: Preliminary findings. Br J Obstet Gynaecol 1995;102:445-447.

24. Hook EB. Contribution of chromosome abnormalities to human morbidity and mortality. Cytogenet Cell Genet 1982;33:101-106.

25. Baird PA, Sadovnick AD. Maternal age-specific rates for Down syndrome: Changes over time. Am JMed Genet 1988;29:917-927.

26. Walker S, Howard PJ. Cytogenetic prenatal diagnosis and its relative effectiveness in the Mersey region and North Wales. Prenat Diagn 1986;6:13-23.

27. Mikkelson $M$. The incidence of Down's syndrome and progress towards its reduction. Philos Trans $R$ Soc Lond B Biol Sci 1988;319:315-324.

28. Priest JH, Fernhoff PM, Elsas LJ, Huether CA. Prenatal diagnosis in metropolitan Atlanta and the impact on autosomal trisomies. Am J Obstet Gynecol 1988;159:1306-1307.

29. Palomaki GE, Haddow JE, Beauregard LJ. Prenatal screening for Down's syndrome in Maine, 1980 to 1993. N Engl J Med 1996;334:1409-1410. 